\title{
Radial artery pseudoaneurysm as a rare very late complication of transradial cardiac catheterization
}

\author{
Radomir Nykl, Jan Precek, Milos Spacek, Martin Sluka, Stepan Hudec, Petr Heinc, Milos Taborsky
}

\begin{abstract}
Aims. Here, we report a case of very late (70+ days) development of pseudoaneurysm on the site of sheath insertion in a 60- year old woman.

Methods. The patient underwent cardiac catheterization using transradial approach.

Results. Despite the transradial approach, which is generally considered as a suitable prevention of this problem, and despite absence of any periprocedural complications, the patient developed a pseudoaneurysm after more than 70 days from the procedure.
\end{abstract}

Conclusions. In some cases, a pseudoaneurysm may develop extremely late after cardiac catheterization. Such an extremely late development of pseudoaneurysm has not been described in literature so far.

Key words: pseudoaneurysm, transradial approach, cardiac catheterization

Received: April 23, 2020; Revised: May 25, 2020; Accepted: June 16, 2020; Available online: June 26, 2020 https://doi.org/10.5507/bp.2020.027

(c) 2021 The Authors; https://creativecommons.org/licenses/by/4.0/

Department of Internal Medicine I - Cardiology, University Hospital Olomouc, Czech Republic Corresponding author: Radomir Nykl, e-mail: radomir.nykl@fnol.cz

\section{CASE REPORT}

We present the case of a 60 -year-old woman with a history of pulmonary hypertension ( 8 years, sildenafil therapy, she had tolerated treprostinil in the past), high blood pressure, dyslipidemia, sleep apnea syndrome, paroxysmal atrial fibrillation and thyroid goiter with normal function. Her chronic medication included the following drugs: sildenafil $20 \mathrm{mg} 3 \mathrm{x}$ a day; apixaban $5 \mathrm{mg}$, metoprolol $50 \mathrm{mg}$, and sertraline $50 \mathrm{mg} 2 \mathrm{x}$ a day; spironolactone $25 \mathrm{mg}$, atorvastatin $20 \mathrm{mg}$, pantoprazole $40 \mathrm{mg}$, furosemide $20 \mathrm{mg}$, and amiodaron $200 \mathrm{mg} 1 \mathrm{x}$ a day. This lady underwent cardiac catheterization due to a suspected coronary arterial disease (via right radial artery, $5 \mathrm{~F}$ Terumo sheath). Her peroral anticoagulation therapy (apixaban $5 \mathrm{mg}$ twice a day) was discontinued the evening prior to the procedure and only resumed the evening after the procedure; 3000 IU heparin was administered intra-arterially prior to the procedure. The result of the examination was negative, sheath insertion was free of complications. A TR band (Terumo, inflatable compressive tape) was applied over the access site inflated with $12 \mathrm{~mL}$ of air, sheath removed. The band was deflated gradually, removed after $4 \mathrm{~h}$. The examination revealed no local or general complications. The patient was discharged from hospital the next day.

More than 2 months later (after 72 days), the sheath insertion site started hurting and two days later, a $2 \mathrm{~cm}$ large pulsating resistance appeared at the puncture site. The patient immediately visited the local hospital where doppler color flow imaging was performed and a pseudoaneurysm $(12 \times 13 \times 15 \mathrm{~mm})$ confirmed (see Fig 1). The patient was sent to our hospital and admitted to the Department of Surgery where she underwent vascular surgery - the hematoma was evacuated, which was followed by resection of the pseudoaneurysm and artery treatment. The patient recovered completely within 3 days and was discharged. She remains asymptomatic at the five months follow-up.

\section{DISCUSSION}

The change of cardiac catheterisation approach to transradial led to a significant reduction in the occurrence of access-site complications (pseudoaneurysm, dissection, hematoma, A-V fistula, radial artery occlusion, spasm, hand ischemia, bleeding). This also applies to pseudoaneurysm (defined as a sac in the artery surrounding tissue with persistent flow from the artery into that $\left.\mathrm{sac}^{1-3}\right)$, the current occurrence is around $0.05 \%$ ) $\left(\right.$ ref. $\left.^{4-6}\right)$. Other factors can affect development of this rare complication (multiple puncture attempts, effect of anticoagulation, inadequate compression or incorrect positioning of TR band, sheath size or catheter size) ( ref. $\left.^{7,8}\right)$, none of which however occurred in this case.

A small defect can be resolved by compression (practically to cause thrombosis of the pseudoaneurysm cavity), a larger one requires surgical intervention (a direct ligation of the defect, excision of the vessel wall with angioplasty, or excision of the radial artery where evidence of collateral arterial flow to the hand is present. The use of thrombin is another treatment possibility ${ }^{7.9}$.

In our case, nothing indicated an increased risk of complications, no problem occurred during the procedure or prior to the discharge. A very long time (74 days) passed before the pseudoaneurysm appeared, which is exceptional; these vascular complications develop generally shortly after the catheterization ${ }^{1-3,6}$. The risk factors 

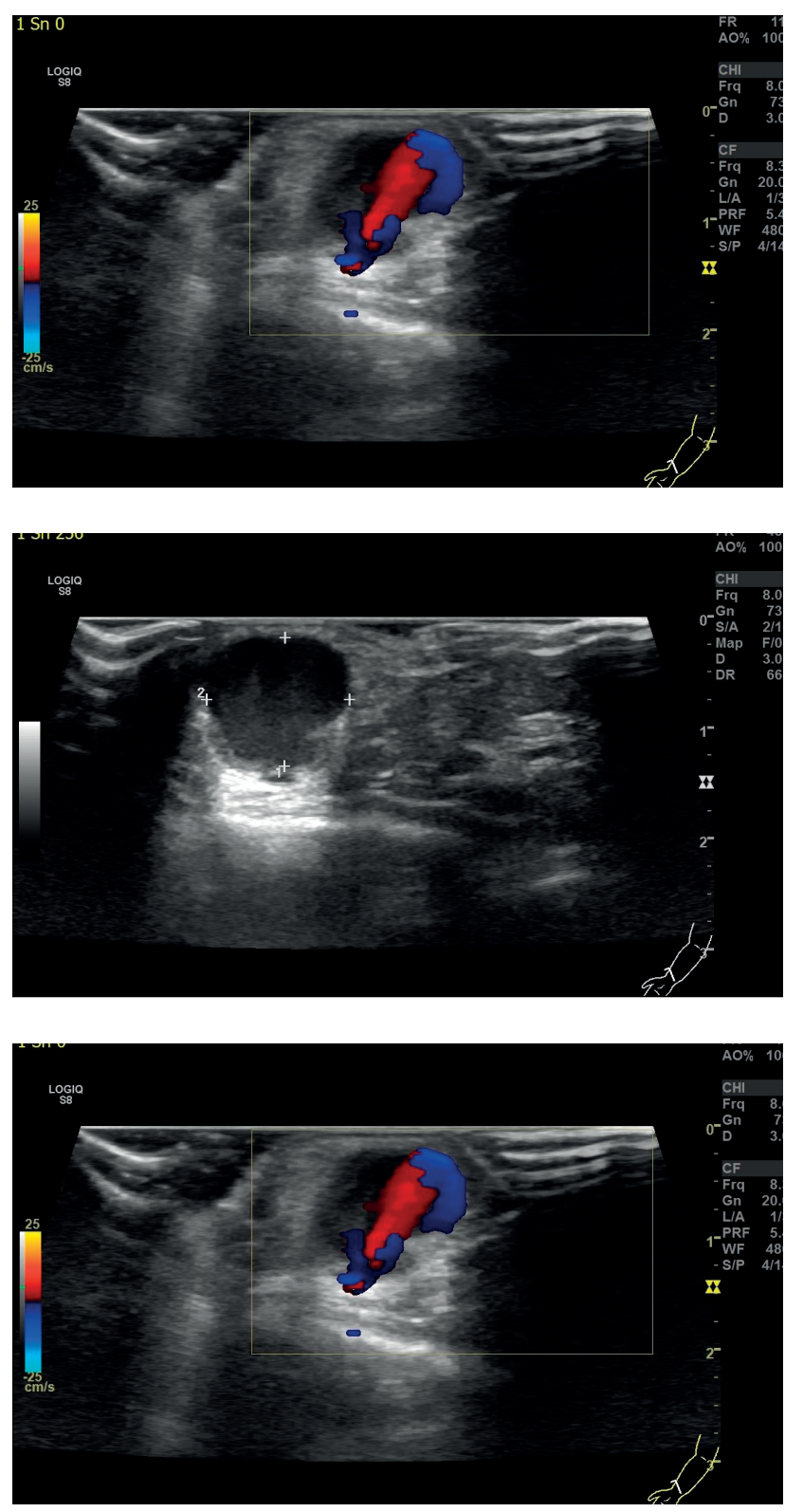

Fig. 1. Doppler ultrasound of the pseudoaneurysm.

of early pseudoaneurysm development are well known (see above); in our particular case, however, we can only speculate what happened exactly. One of the possibilities is a gradual development that has not been noticed by the patient. Another possible etiology is incomplete healing of the sheath insertion location that facilitated a pseudoaneurysm development following a secondary stress (overstretching, minor injury/blow, etc.). Both these possible explanations are however a pure speculation only. Anyway, no definite risk factor can be highlighted in this extremely rare case. Normally, we advise patients to be careful with the upper limb and observe the development for 5 days after a surgery, we have never experienced such a late development of an aneurysm so far.

\section{CONCLUSION}

The incidence of local complications of cardiac catheterization including development of pseudoaneurysm is known to be very low when using the radial approach. Its early occurrence is reduced by the quality of the puncture, the size of the instrumentarium and adequate compression. This case however demonstrates that we must be aware of the possibility of even very late complications that have not been reported in the literature so far.

Author contributions: RN: care for the patient, manuscript writing, literature search, JP, MS, MS, SH, PH, MT: care for the patient, literature research, final approval.

Acknowledgements: Many thanks to Dr. Jaroslav Janosek for his valuable comments.

No financial support was used.

Conflict of interest statement: The authors state that there are no conflicts of interest regarding the publication of this article. None declared.

\section{REFERENCES}

1. Katzenschlager R, Ugurluoglu A, Ahmadi A, Hülsmann M, Koppensteiner R, Maca T, Minar E, Stümpflen A, Ehringer $H$. Incidence of pseudoaneurysm after diagnostic and therapeutic angiography. Radiology 1995;195:463-6.

2. Sanmartín M, Cuevas D, Goicolea J, Ruiz-Salmerón R, Gómez M, Argibay V. Vascular complications associated with radial artery access for cardiac catheterization. Rev Esp Cardiol 2004;57:581-4.

3. Kalapatapu VR, Shelton KR, Ali AT, Moursu MM, Eidt JF. Pseudoaneuysm: A review. Curr Treat Cardiovasc Med 2008;2:173-83.

4. Eichhöfer J, Horlick E, Ivanov J, Seidelin PH, Ross JR, Ing D, Mackie K, Ridley B, Schwartz L, Barolet A, Dzavik V. Decreased complication rates using the transradial compared to the transfemoral approach in percutaneous coronary intervention in the era of routine stenting and glycoprotein platelet Ilb/Illa inhibitor use: A large single-center experience. Am Heart J 2008;156:864-70.

5. Tatli E, Buturak A, Cakar A, Vatan BM, Degirmencioglu A, Agac TM, Kilic $\mathrm{H}$, Gunduz H, Akdemir R. Unusual vascular complications associated with transradial coronary procedures among 10,324 patients:case based experience and treatment options. J Interv Cardiol 2015;28(3):305-12.

6. Llácer Pérez M, González Jiménez JM, Jiménez Ruiz A. Pseudoaneurysm in the radial artery after catheterization. Rev Esp Anestesiol Reanim 2006;53(2):119-21.

7. Kanei Y, Kwan T, Nakra NC, Liou M, Huang Y, Vales LL, Fox JT, Chen JP, Saito S. Transradial cardiac catheterization: A review of access site complications. Catheter Cardiovasc Interven 2011;78:840-6.

8. Collins N, Wainstein R, Ward M, Bhagwandeen R, Dzavik V. Pseudoaneurysm after transradial cardiac catheterization: Case series and review of the literature. Catheter Cardiovasc Interv 2012;80:283-7.

9. D'Achille A, Sebben RA, Davies RP. Percutaneous ultrasound-guided thrombin injection for coagulation of post-traumatic pseudoaneurysms. Australas Radiol 2001;45:218-21. 